\title{
POWER AND JUSTICE: AN HYPOTHESIS IN THE ANTHROPOLOGY OF LA W*
}

\author{
RENE R. GADACZ**
}

\begin{abstract}
What characteristics of an interpersonal dispute determine the type of forum that is best suited for processing that dispute? When is a less formal approach such as mediation preferable to court action and vice-versa? Attention will be given to the disputant's justice goals. Third-party dispute forums are analyzed in terms of where power is located during all stages of the dispute resolution procedure. An hypothesis is offered which predicts that the most appropriate locus of power, be it with the disputants themselves, with a third-party such as a mediator, or with "rules" of procedurc is a function of the disputant's justice goals, the relationship between the disputants, and the costs of the dispute. The hypothesis is related to three types of third-party forums mediation, arbitration, and adjudication.
\end{abstract}

\section{INTRODUCTION}

Heated disagreements can of ten arise between family members, among friends and co-workers, neighbours, merchants and consumers and in other social relationships that are an inevitable part of daily living. Many disputes arising in these contexts are easily managed by the parties involved by directly confronting each other, by ignoring the problem or simply by avoiding the other person. However, a substantial number of disputes are not handled satisfactorily by these means and are eventually brought to the attention of such third-parties as the police, the courts, clergy, the ombudsman and so forth. Often by the time the third-party becomes involved the conflict may have intensified and the parties have likely attached symbolic value to the outcome.

Despite some progress in the anthropology of law in recent years in the study of dispute processing, ${ }^{1}$ little is actually known about the reasons why people choose to seek assistance from a third-party rather than "lumping it" or working things out for or among themselves. Why might an apartment dweller decide to call the police about a neighbour's noisy parties instead of approaching his or her landlord or, if there is one, the building tenant association? The anthropology of law has focused on the dispute process and on dispute resolution but seems to have neglected to consider the value-sphere of the dispute, or what the disputes mean to the individuals themselves.

In addition, the questions of which forum will be (or ought best be) pursued and why people pursue "justice" remains, in this writer's

- This article is a development of ideas originally presented at a session on the anthropology of law organized by the author, and chaired by Professor Barbara Yngvesson, at the Law and Society Association meetings, held at Amherst College, Massachussetts, June 12-14 1981. The ideas of informalism and mediation are discussed in my book (see note 1 below). I wish to acknowledge the Social Sciences and Humanities Research Council of Canada for its current funding support.

* Department of Anthropology, University of Alberta.

1. L. Nader and L. Singer, "Dispute Resolution: What are the Choices", (1976) 51 California State Bar Journal 281; S. Merry, "Going to Court: Strategies of Dispute Management in an American Urban Neighbourhood", (1979) 13 Law and Society Review 891; L. Nader and H. Todd, The Disputing Process (1978); F. Synder, "Anthropology, Dispute Processes and Law: A Critical Introduction", (1981) 8 British J. of Law and Society 141; R. Gadacz, Towards an Anthropology of Law in Complex Society: An Analysis of Critical Concepts (1982). 
estimation, relatively unexplored in the anthropological literature on people in conflict. These questions are, moreover, at the heart of research and experiments on the use of alternatives to civil and criminal litigation through negotiation, mediation, arbitration and various other attempted judicial reforms. ${ }^{2}$ This article explores possible relationships between choice of forums and the pursuit of justice in an attempt to bring people back into the discussion of disputes, and to look at the values behind the disputes. The following hypothesis is advanced: The preference for where power should be located during the decision phase of the procedure will be a function of the particular justice goals of the parties involved, while the costs of the dispute and the type of relationship between the parties will determine the type of justice forum preferred. The notion of justice will be examined first.

\section{JUSTICE AND JUSTICE-ORIENTED GOALS}

One point that is made in the literature on dispute processing forums is that the nature or the kind of relationship between disputants will have a major impact on the choice and suitability of a particular law forum. In turn, the relationship between the parties will be tempered by the goals or objectives of each party in pursuing a particular dispute. Most researchers agree that if the parties are involved in a "multiplex" or on-going relationship then conflict between them may in fact be exacerbated in the process of adversarial adjudication. The same relationship might then provide impetus for reaching settlement in a voluntary, more informal, forum. ${ }^{3}$

There may be a relationship between the kind of relationship that exists between contending parties, the nature of the conflict, and the pursuit of justice goals. The desire for justice is an important and of ten inadequately understood goal. ${ }^{4}$ Whether one is viewing justice in terms of rights, retribution, restitution, obligation or fair procedure it is the concern for justice that is in fact the "ultimate value" that disputants attach to dispute outcomes. The individual, it is suggested, turns to a third-party in an effort to restore justice to his or her life. This is readily apparent from anecdotal evidence of persons involved in conflict. Statements such as "It's not so much the money as it is the principle of the matter" or "How can I ever get my children to believe in justice if they see him get away with this?" are commonly heard. The symbolic values that lead to conflict escalation are of ten values of justice - the concern for rights, obligations and "just common decency". What would otherwise be a

2. R. Danzig, "Toward the Creation of a Complementary Decentralized System of Criminal Justice", (1973) 26 Stanford Law Review 1; P. Nonet and P. Selznick, Law and Society in Transition (1978); P. Gulliver, Disputes and Negotiations: A Cross Cultural Perspective (1979); R. Horrocks, "Alternatives to the Courts in Canada" (1982) 20 Alberta Law Review 326; R. Tomasic and M. Feeley, Neighborhood Justice: Assessment of an Emerging Idea (1982) [see my review of this book in (1984) 22 Alberta Law Review 311]; L. Nader, No Access to Law: Alternatives to the American Judicial System (1980).

3. See, for example, W. Felstiner, "Influences of Social Organization on Dispute Processing" (1974) 9 Law and Society Review 63; J. Starr and B. Yngvesson, "Scarcity and Disputing: Zeroing-in on Compromise Decisions" (1975) 2 American Ethnologist 553.

4. For a valuable treatment of the subject of justice, see K. Cook and K. Hegtvedt, "Distributive Justice, Equity and Equality" (1983) 9 Annual Review of Sociology 217. 
minor dispute over a few inches of grass is quickly interpreted as "he's not respecting my right to property". A noise problem between neighbours becomes critical when one party asserts that a man has a right to peace and quiet in his own home, and when the other neighbour counters that she has a right to listen to whatever type of music she likes. Both feel threatened and personally abused because their rights are not being respected, and demand that the situation be set right again. ${ }^{5}$

In these and other examples people might very well be engaged in behaviour that would appear irrational to the outside observer. They might spend far more money litigating a boundary claim than the disputed property is worth. Here, the disputants are preoccupied with achieving such symbolic goals as "winning" or avoiding "loss of face". These interpretations are however made by an observer not involved in the conflict, rather than by the participants themselves. The disputants are much more likely to perceive their goals to be "justice". As a heuristic it is necessary to give as much credence as possible to their perceptions, rather than imposing an analytical interpretation upon the situation. It is also necessary to keep in mind that definitions and an understanding of justice among and between individuals will vary considerably. Essentially, the concept of justice can be thought to consist of two components: procedural fairness and distributive fairness.

Procedural justice refers to the individual's perception of the fairness of rules or other procedural components that are part of the social system that regulate whatever process, legal as well as non-legal, the individual is involved in. In a situation where resources are being allocated there are different criteria in addition to fair procedures for determining what is a "just" distribution. There can be a justice of "equality", where all parties receive an equal share of the goods, or justice can be based on some principle of proportionality. One theory dealing with the latter is equity theory, which defines a fair distribution as one in which an individual's outcome is proportional to his or her input. Another approach defines justice as a distribution based primarily on "need", with minimal regard for other factors. While justice according to need of ten seems to play only a minor role in capitalist societies, ${ }^{6}$ it has been pointed out that it can be a common expression of fairness in intimate social relations, as for example among relatives and family members.

Thus far justice has been discussed in terms of procedure and distribution of resources. There is however an additional dimension of fairness that might be termed "restorative" justice. Restorative justice is concerned with righting wrongs, that is, restoring a situation or relationship to wholeness following damage, injury or some other wrongdoing. Whereas distributive justice has to do with a person's concern with getting resources or positive benefits he or she believes he or she is entitled to, restorative justice often deals with seeking redress for injury and suffering, for example, psychological damage, mental cruelty and so on. One

5. My current research is precisely on this point; see my manuscript "Rights as a Weapon of Social Conflict", read at the meeting of the Canadian Sociology and Anthropology Association, Ottawa June 1982.

6. M. Walzer, Spheres of Justice: A Defence of Pluralism and Equality (1983). 
might say that distributive justice is directed at preventing injury or injustice, while the idea of restorative justice is invoked after a transgression has been committed. A dispute over who will get the watermelons from the vine on the property line changes dramatically when the melons disappear one dark night. In the former case one may be concerned with equity inputs such as planting and cultivating the vine, while in the latter situation the concern is much more likely to be one of retribution.

The notion of restorative justice is of ten directly related to an attack on one's psychological or physical well-being. ${ }^{7}$ These "non-material" or intangible resources are generally not included within the domain of distributive justice. This aspect of justice deserves more attention in the anthropology of law and the dispute processing literature than has been the case.

Our courts are filled with people seeking redress for injuries of various types. To the extent that an injured party demands restorative justice, this can have a profound ef fect on the course of the conflict in his or her social relations. The idea of restorative justice includes several significant approaches to remedying wrongs, such as retribution, restitution, compensation and forgiveness. At one level they all share a common goal, which is restoring justice to a particular situation. However, closer examination reveals that strategies for accomplishing restoration differ dramatically. With retribution the injured party requires that the one responsible for creating the injustice suffer in a way that is commensurate with the way he or she, the victim, has suffered (e.g. "an eye for an eye", perhaps even "death for an insult"). ${ }^{8}$ The point is the justice is achieved when the perpetrator has been punished by the actual victim or someone acting on his or her behalf.

Another way to "make things right again" is to replace or renew whatever has been damaged. With restitution the smashed fender is taken to the body shop and the offending driver pays the bill. The damaged fence is rebuilt, or the injured person receives payment for lost wages resulting from time off work. Here, the victim receives some material good or service to repair or replace that which was damaged; with retribution the satisfaction realized by the victim is primarily psychological. Compensation is similar to restitution in that the needs of the victim are at issue. However, it may not always be possible to restore that which was lost or damaged. Grandma's broken china cannot be replaced, nor can a severed arm or a dead relative. In such situations it is nevertheless possible for the perpetrator to attempt to address directly the needs of the victim through some form of compensation ${ }^{9}$ such as money,

7. See for example H. Hogbin, "Shame: A Study of Social Conformity in a New Guinea Village" (1947) 17 Oceania 273; M. Gluckman, "Gossip and Scandal" (1963) 4 Current Anthropology 307; F. Bailey, The Tactical Uses of Passion: An Essay on Power, Reason, and Reality (1982).

8. In anthropology, the literature on feuding discusses this aspect of achieving justice; see for example J. Black-Michaud, Cohesive Force: Feud in the Mediterranean and the Middle East (1975) and G. Kressel, "Sororicide/Filiacide: Homicide for Family Honor" (1981) 22 Current Anthropology 141.

9. A case in point would be workmen's compensation; see, for example, C. Reasons, L. Ross and C. Paterson, Assault on the Worker: Occupational Health and Safety in Canada (1981) [see my review of this book in (1983) 21 Alberta Law Review 391]. 
material aid or performing a service for the victim. It is not unusual to claim financial compensation for "pain and suffering". Finally, another way to restore justice is through forgiveness. While rarely discussed in the literature, this approach is of some importance, particularly in intimate relationships. Justice is restored by an admission of wrongdoing and so by the cancellation of the debt. Not all of these approaches to what is termed restorative justice are mutually exclusive - it is quite possible for two or more of them to be combined in any given situation.

Related to this concept of restorative justice are several issues that are concerned with determining the offender's future behavior and, ultimately, the vindication of social values. The victim perhaps may not be as concerned with redressing the current situation as he or she is in gaining some assurance and satisfaction that the incident will not be repeated. Such justice-seeking behavior can serve to vindicate both personal and societal values. The administration of punishment and the delivery of restitution and/or compensation serves to reaffirm those beliefs and values which have been violated. The offender's attitude and demeanor can also significantly affect the kind of justice asked for. Does the offender acknowledge any wrongdoing on his or her part? And if so, does he or she demonstrate any remorse for what has happened? If the offender is remorseful the victim may come to believe that the incident is not likely to be repeated and conclude that justice can best be restored through forgiveness, or perhaps through restitution or compensation as a kind of last resort. Should the offender fail to demonstrate remorse however, or even appear scornful of the victim's values, the victim is more likely to demand punishment or a much greater amount of compensation or restitution. Social beliefs and values tend to have strong affective qualities attached to them; to have one's perceived rights violated can produce anger, but to have the culprit refuse to acknowledge those rights or laugh at them is nothing less than infuriating.

What of the relationships that exist between individuals involved in disputes? In looking at relationships between parties, two dimensions can be identified: the affective and the functional. The affective character of the relationship can be either positive or negative, and the accompanying emotions can be either very strong or weak. Presumably by the time people seek help from a third-party the affective quality of their relationship has deteriorated and is fairly negative. However, it is the functional qualities of the relationship between parties that is most of ten referred to in the literature on dispute forums. Parties interact because they share common space, are dependent in some way on each other, or are in competition. Three kinds of functional relationships might be delineated. In interdependent relationships there is a mutually valued exchange of services or resources and when the relationship is going well the effect is mutually facilitative and advantageous. It is not necessarily true, however, that the individuals will like each other or even have personal contact. Where the relationship is co-existent, the parties use common space or resources but do not require anything of each other except to be left alone. Next-door neighbours in an apartment building are a good example of this. It is only when noise penetrates the walls or trash collects in the corridors that problems arise. Again, whatever affect exists in the 
relationship can be either positive or negative. Finally, parties engaged in what is called a zero-sum competition are in a conflicting relationship. One person's gain is the other's loss. While the functional relationship is necessarily competitive it may be either personalized or depersonalized through roles and conventions. Cross-cutting all of these functional aspects are of course other factors, such as the duration and historical time depth of the relationship. Is it long or short term? Does the relationship exist primarily in the past or is future interaction anticipated?

\section{THIRD-PARTY FORUMS}

This article now turns to discuss some of the dynamics and dimensions of three commonly recognized third-party disputing forums. An attempt will be made to delineate some of the relevant dimensions of mediation, arbitration and adjudication; the concern is with power and control in these qualitatively different situations. Power and control over both the proceedings and decision-making may be thought of as being divided among three entities, namely, the disputants, the third-party (e.g. mediator, arbitrator or judge) and the prescribed rules or laws (e.g. the "rule of law"). While "rules" is being used here in a broader sense than "laws", the emphasis is on those rules that are codified or in some way formalized and which pertain to procedure.

At one end of the spectrum, negotiation (though not, strictly speaking, a third-party forum) is a situation wherein the disputants have total control over both the presentation process, that is, the debate and discussion of the "evidence" and details of the incident(s), and the final decision or outcome of the dispute. With mediation, by contrast, a third-party now structures the presentation for the disputants though the disputants still retain decision-making powers with respect to the outcome of the dispute and the final settlement. Similarly, in arbitration the third-party now assumes the power of making binding decisions in addition to regulating the interaction that is going on. With adjudication, the other end of the spectrum, presentation is much more formal and closely follows rules of evidence and rules of procedure (e.g. "due process"). In addition, the decision powers of the third-party come to be more narrowly determined by the rules themselves and by precedent. Decisions are considered final and binding.

The structural dimensions of these forums can affect the dynamics of the interaction between the individuals involved. The lack of formal procedure in mediation (and in some cases, arbitration), for example, gives greater control to the disputants during the presentation or input stage of the entire process. Procedural rules, on the other hand, tend to place the disputants into roles they are obliged to play. Since the people involved must follow more or less explicit rules of procedure the entire proceeding is effectively depersonalized. Because formalized rules of conduct are followed the process also continues with a minimum of trust between the parties. Informal forums tend to focus closely on the substantive fairness or actual outcome of the decision. But in formal forums "rules" assume a much greater role in both the presentation and decision stages and justice comes to be viewed increasingly in procedural terms; as well, a salient feature of procedural justice is that the range of issues are quite 
narrowly defined. In other words, an issue can be deemed relevant only if there are rules or laws pertaining to it. Justice forums which are highly oriented towards procedure also generate a need for specialists in procedure. What may happen is that proceedings may become increasingly technical or otherwise confusing to the disputants who are untrained in procedure and a definite advantage accrues to those who have experience or training in procedure.

In the less formal of the third-party disputing forums, the problemsolving orientation focuses on the specific issues or problems and what may be done to remedy the situation. Who is to blame for the current mess is not really the issue; rather, the emphasis is on what can be done to make it better. The "punitive" approach in a formal setting on the other hand requires a determination of guilt or blame. Punishment also requires a legitimate authority to administer the penalty. Such an authority is not required for the problem-solving orientation of the informal setting. Where the disputants actually hold decision-making power this implies a willingness to accord some power and status to the other person. While the parties may be skeptical or openly suspicious of each other's motives, the assumption is that the other person will not grossly violate principles of decency and fair play. It is also assumed that one party may need to bargain or accept something less than ideal in order to achieve a resolution. When decision control passes beyond the disputants, however, there is implicit recognition that the parties are either unwilling or unable to resolve the situation themselves - they are going for broke. Finally, individuals face a number of costs in pursuing a dispute into a formal third-party forum. ${ }^{10}$ Some of these costs, such as fees, forfeited wages and time spent in the dispute can, if needed, be readily quantified and measured by the researcher. Other costs, such as the unpleasantness of court, personal confrontation or adverse publicity, are more psychological in nature and consequently are more difficult to "measure". On the positive side, the individual may also realize psychological rewards such as the opportunity for vindication or to draw attention to his or her cause. In an informal forum, or in negotiation where only the disputants are involved, costs, both material as well as psychological, are negligible and the publicity generated by a formal proceeding is also avoided.

\section{POWER, JUSTICE AND CHOICE OF FORUM}

Having considered some of the characteristics of disputes, some features of dispute forums and what may be involved in pursuing justice, the discussion returns now to the hypothesis and how certain factors, just mentioned, relate to determine the suitability of a given forum for a particular dispute with respect to specific justice goals. Since retribution requires the determination of guilt and subsequent sanction, it can be hypothesized that this goal can best be met in a forum where decision control resides with a legitimate power for such judgements, that is, with someone other than the disputants themselves. In state societies such

10. For an enlightening discussion, see M. Feeley's The Process is the Punishment: Handling Cases in a Lower Criminal Court (1979). 
power rests ultimately with the state and its law; sanctioning in this context necessitates an adjudicative forum. In other political contexts such power may rest with the disputants and/or their families. In the case of restitution and compensation where equity has to be determined the input of each party covers a wider range. Decisions which are confined to rules or precedent may be too narrow to sufficiently encompass the concerns of the disputants, and the parties might otherwise prefer a forum where decision-making powers rest either with them or a third-party.

The implications of the types of relationships between disputants on their final choice of forum and on the kind of justice they are pursuing might be outlined as follows. In functionally interdependent relationships we might expect them to prefer procedures which produce minimal additional strain on the relationship. This could involve a relatively nonadversarial approach, one that emphasizes problem-solving rather than determination of guilt or punishment. In other words the parties prefer "third-party" power rather than "rules" power during the proceedings. When relationships are co-existent the parties have less incentive to preserve harmony though they still have some interest in not totally alienating each other and antagonizing one another. They might display more ambivalence over choice of forums. However, with little stake in preserving any kind of relationship, when the relationship is a competitive or conflicting one, the parties will most likely move toward a forum employing an adversary procedure.

These predictions may at times be tempered by whatever affect exists in the relationship. Positive affect would encourage cooperative approaches, while extreme negative affect and accompanying high levels of distrust would likely lead to more formal proceedings. Affect can also make confrontation so unpleasant that a more depersonalized (that is, formal) setting would be preferred.
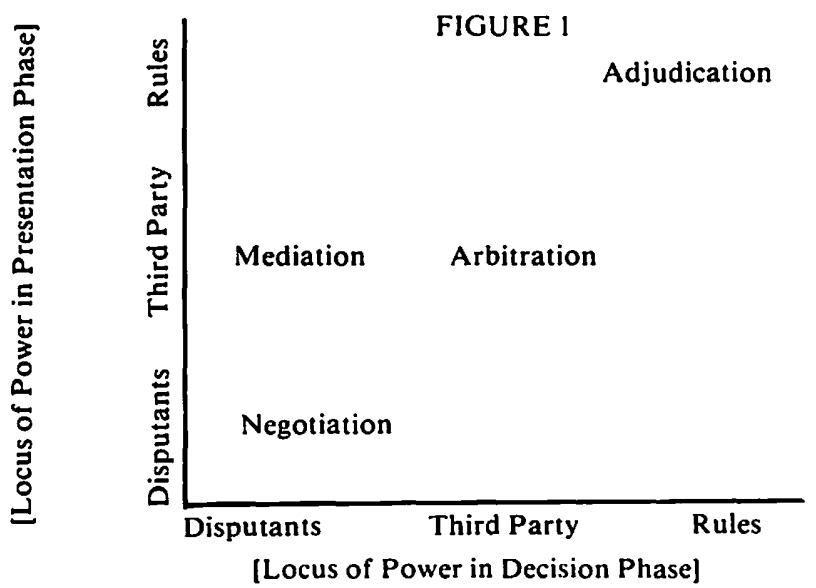

\begin{tabular}{rll} 
& Negotiation & \multicolumn{1}{c}{ Adjudication } \\
Justice: & Distributive/Restorative & Procedural \\
Mood: & Cooperative/Problem-solving & Adversarial/Punitive \\
Issues: & Broad & Narrow \\
Formality: & Low & High \\
S Costs: & Low & High \\
Time: & Low & High \\
Publicity: & Low & High
\end{tabular}




\section{CONCLUSION}

When involved in an interpersonal dispute people may choose to deal with the problem directly, ignore it and try to avoid the other person, or they might enlist the aid of a third-party. Should the parties decide to choose third-party assistance there are a variety of possible forums available to them. The aim in this article has been to understand the type of forum preferred for a given dispute. Particular attention has been given to those goals which are important to an individual's sense of justice, that is, what he or she feels he or she deserves or is entitled to in a certain situation. Justice has been described in terms of retribution, restitution, compensation and forgiveness. Interacting with the justice goals in determining the choice of forum are of course both the standing relationship between the parties and the costs of the action. The relationship between the parties is viewed in functional terms and costs are described as being both economic as well as psychological in nature. Disputing forums in this article were described with respect to the locus of power among the disputants, the third-party intervener (when called for) and formalized rules during the presentation and decision stages of the procedure. The hypothesis that was presented states that preference for a specific forum results from an interaction between the goals of the parties, their mutual relationship and the attendant costs. It predicts that the preference for where power should be located during the decision phase is going to be influenced primarily by the participant's justice goals, while the type of presentation that is preferred will be determined to a large extent by the costs involved and the functional relationship between the parties.

The purpose of the hypothesis, again, is not so much to predict how to make a dispute "turn out right" or to arrive at a resolution as it is to try to outline the minimal conditions there are that might reduce the probability of failure. The discussion of restorative justice did not attempt to explain the etiology of justice concerns, nor did it predict what factors in the person or situation would give rise to one formulation of justice rather than another. The discussion began with the experience of injustice and simply asked, given that people have their own particular understanding of what justice is, how that will affect what happens next in the dispute.

As it is presented here the hypothesis has certain weaknesses. While perhaps it is more detailed than other theoretical formulations in this area of law research it is still a difficult one to quantify - measuring a "justice goal" is no easier than measuring any other type of "motive" and phenomena such as "psychological costs" may remain empirically elusive. There is also a lack of specificity in describing the exact interactions one could anticipate, particularly how "costs" and "relationships" might interact to determine the preference for a particular type of presentation. The difficulties however are probably no greater than those encountered in an examination of any other real-life phenomena. The issues raised in this article, it is suggested, hold sufficient significance for both a conceptual understanding of dispute behavior and the development of "legal" or "social control" mechanisms for dealing with that behavior. 